\title{
Los Actos de Administración: la Figura del Dictamen Jurídico
}

\section{The Acts of Administration: the figure of the Legal Report}
Os Atos de Administração: a Figura do Ditame Jurídico

\section{Les actes de l'administration: la figure de l'opinion juridique}

\section{\begin{tabular}{l|l} 
Osvaldo Héctor Bezzi & $\begin{array}{l}\text { Universidad Nacional } \\
\text { de La Plata }\end{array}$
\end{tabular}}

Revista Derechos en Acción

Año 3/Nº 9 Primavera 2018, 148-166

DOl: https://doi.org/10.24215/25251678e217

ORCID: https://orcid.org/0000-0002-4404-6372

Recibido: 08/08/2018

Aprobado: 21/09/2018

Resumen: La actividad interna de la Administración ha sido objeto de especial tratamiento en la doctrina italiana, que ha efectuado una distinción basada en la eficacia: actos internos y externos. Esta distinción ha generado opiniones divergentes de la actividad interorgánica, la cual comprendería a los actos dirigidos fundamentalmente a otros órganos de la Administración y que agotan en la organización administrativa su eficacia. El trabajo desarrolla la figura del dictamen. En el ámbito de la actividad preparatoria de la decisión administrativa cobra relieve la función de la Administración consultiva, pues mediante ella se ilustra de manera anticipada al dictado de un acto administrativo, con el respectivo juicio al órgano de la Administración activa con competencia decisoria en la materia de la que se trate. El resultado de dicha actividad se plasma en un dictamen, el cual consiste en un juicio fundado en una

\footnotetext{
1 El presente trabajo contó con la colaboración de Lucas M. Rueda. https://orcid.org/00000001-5534-3439.
} 
ciencia determinada, que emiten organismos técnicamente calificados a fin de colaborar en el encuadre y comprensión del asunto bajo análisis, para permitir así que el órgano de la Administración activa efectúe una decisión ajustada al ordenamiento jurídico, tendiendo a satisfacer de mejor manera los principios de justicia y legalidad.

Palabras claves: Administración pública; actividad interna; dictamen.

Abstract: The internal activity of the Administration has been given special treatment in the Italian doctrine, which has made a distinction based on efficiency: internal and external acts. This distinction has generated divergent opinions of the inter-organic activity, which would include the acts directed fundamentally to other organs of the Administration and which exhaust their effectiveness in the administrative organization. The work develops the figure of the opinion. In the field of the preparatory activity of the administrative decision, the role of the consultative Administration is highlighted, as it illustrates in advance of the issuance of an administrative act, with the respective judgement to the active body of the Administration with decision-making competence in the matter in question. The result of this activity is reflected in an opinion, which consists of a judgment based on a specific science, issued by technically qualified bodies in order to collaborate in the framing and understanding of the matter under analysis, thus allowing the active administrative body to make a decision adjusted to the legal system, tending to better satisfy the principles of justice and legality.

Keywords: Public administration; internal activity; report.

Resumo: A actividade interna da Administração tem sido objecto de tratamento especial na doutrina italiana, que fez uma distinção baseada na eficácia: actos internos e externos. Esta distinção tem gerado opiniões divergentes de atividade interorganizacional, o que incluiria atos dirigidos principalmente para outros órgãos da Administração e que Destroem a eficácia da organização administrativa. 0 trabalho desenvolve a figura da opinião. No campo da actividade de preparação do decisão administrativa é realçado o papel do corpo Consultivo, como por isso é ilustrado previamente para a emissão de um acto de administração, com o respectivo julgamento para a gestão activa corpo com poder de decisão no assunto. 0 resultado desta atividade é refletida em uma opinião, que é um baseado em uma ciência particular, que emitem 
tecnicamente qualificado para colaborar na definição e compreensão do assunto em julgamento agências de análise, permitindo assim que 0 corpo do A administração ativa toma uma decisão ajustada ao sistema legal, tendendo a melhor atender aos princípios de justiça e legalidade.

Palavras-chave: Administração pública; atividade interna; parecer

Résumé: L'activité interne de l'Administration a fait l'objet d'un traitement spécial dans la doctrine italienne, qui établit une distinction fondée sur l'efficacité: actes internes et actes externes. Cette distinction a généré des opinions divergentes sur l'activité interorganique, qui incluraient les actes visant fondamentalement d'autres organes de I'Administration et qui épuiseraient dans I'organisation administrative leur efficacité. Le travail développe la figure de l'opinion judiciaire. Dans le domaine de l'activité préparatoire de la décision administrative, le rôle de l'administration consultative est mis en évidence, car il illustre par avance la délivrance d'un acte administratif, avec l'arrêt correspondant à I'organe de l'administration active ayant une compétence déterminante en matière de celui concerné. Le résultat de cette activité est exprimé dans un avis qui consiste en un jugement basé sur une science spécifique, émis par des organismes techniquement qualifiés afin de collaborer à la définition et à la compréhension du sujet analysé, afin de permettre à l'organe d'administration prend une décision adaptée au système juridique, tendant à mieux respecter les principes de justice et de légalité.

Mot-clés: Administration publique; activité interne, avis juridique

\section{La llamada actividad interna, su relación con el régimen jurídico de los actos administrativos; los actos de administración}

La actividad interna de la Administración ha sido objeto de especial tratamiento en la doctrina italiana, que ha efectuado una distinción basada en la eficacia: actos internos y externos. Esta distinción ha generado opiniones divergentes de la actividad interorgánica, la cual comprendería a los actos dirigidos fundamentalmente a otros órganos de la Administración y que agotan en la organización administrativa su eficacia. ${ }^{2}$ 
En forma liminar cabe referir que un examen histórico de las relaciones orgánicas revela que la negación del carácter jurídico de las normas de organización administrativa se fundó en que en ellas puede faltar el carácter fundamental de la alteridad, dato que se ha predicado como esencial de la norma jurídica; no obstante ello es dable ponderar expresando el razonamiento que efectuara Fernando Garrido Falla: “...es la existencia del Derecho administrativo la que determina la juridicidad de esas normas de organización"3.

Por otra parte corresponde señalar que en la doctrina existen divergencias en relación con el alcance que corresponde asignar a la actividad interna ${ }^{4}$. Así, Juan Francisco Linares al abordar la temática discrimina entre actividades domésticas, interorgánicas e interadministrativas, especificando que la primera clase designa "la actividad de cada órgano, que no sea interorgánica, sino 'simplemente orgánica' o 'doméstica', por la cual se ejerce una competencia cerrada, en el sentido de que no se traduce en procesos de relación con otros órganos o con particulares" ; por su lado, la actividad interorgánica traduciría

2 Por ejemplo, ver ZANOBINI, Guido, Curso de Derecho Administrativo, Volumen I, Parte General, páginas 343/345.

3 GARRIDO FALLA, Fernando "Las Transformaciones del Régimen Administrativo", publicado en Estudios de Administración, Instituto de Estudios Políticos, Madrid, 1954, página 17.

4 Ver Fernando R. GARCÍA PULLÉS, en su meduloso estudio "Actividad administrativa interna, interorgánica e interadministrativa", publicado en la obra colectiva "Acto Administrativo y Reglamento", Jornadas organizadas por la Universidad Astral, Facultad de Derecho, Ediciones Rap S.A., páginas 335 y ss. Ver también POLITI, Adela, "Los Actos Interorgánicos", publicado en la obra colectiva Acto Administrativo, Cátedra de Derecho Administrativo, Guido Santiago TAWIL Director, Capítulo 2, páginas 17/26 y GALLI BASUALD0, Martín, “Los Actos Interadministrativos", publicado en la obra colectiva Acto Administrativo, Cátedra de Derecho Administrativo, Guido Santiago TAWIL Director, ob. cit., Capítulo 3, páginas 27/36.

5 LINARES, Juan Francisco, Derecho Administrativo, ob. cit., páginas 307 y ss. Los ejemplos dados por este talentoso jurista revelan el reducido alcance que le otorga a esta clase de actividad, ya que ella estaría configurada por operaciones tales como la recepción de presentaciones que realiza una mesa de entradas, la compaginación de expedientes, la realización de consultas verbales, redacción de memorandos, servir café. Se advierte entonces que se trataría de meros hechos que muchas veces ni siquiera podrían ser conceptualizados como actos. 
una relación entre meros órganos "no personalizados" de la Administración, la cual se ejercería a través de actos, algunos de los cuales serían "administrativos" y otros "de administración". Por otro lado, la "actividad interadministrativa" o "intersubjetiva" sería aquella mediante la cual se relacionan dos o más personas estatales.

Miguel Santiago Marienhoff sostuvo que la actividad interna de carácter general (v. gr.: instrucciones y circulares) no se concreta en actos administrativos sino en actos de administración cuyos efectos no trascienden al exterior. Así, afirmó: "Excepcionalmente esta actividad puede dar lugar a un acto administrativo 'stricto sensu', cuando por el contenido o alcance de la misma trascienda o exceda el mero ámbito de la Administración Pública, incidiendo en la esfera jurídica de terceros", ejemplificando con la hipótesis de que por aplicación de un reglamento interno se vulneren derechos de un agente o se incida en el status de un administrado ${ }^{7}$.

En este orden de ideas, como dijo Jean Rivero, la circular es, en principio, un acto interior puro, destinado solo a los agentes del servicio, que se entiende que conforman en virtud de la obediencia jerárquica, pero sin efecto respecto de los administrados, que la ignoran muy a menudo. Este autor advierte, sin embargo, que si bajo forma de circular se modifica la situación de estos últimos el Consejo de Estado no duda en descubrir que ella importa una verdadera decisión reglamentaria contra la cual declara procedente el recurso por exceso de poder ${ }^{8}$.

6 Ejemplos serían las instrucciones generales, los reglamentos internos y otros individuales como las órdenes de servicio, las sanciones disciplinarias, y los dictámenes. De tal modo, se aprecia que para este autor la locución "interorgánica" también comprendería aquellas que se establecen entre los diversos cargos establecidos en una determinada estructura organizacional, ver LINARES, Juan Francisco, Derecho Administrativo, páginas 308/309.

7 MARIENHOFF, Miguel S., Tratado de Derecho Administrativo, Tomo II, páginas 247/248; ver también su estudio "Actividad Interorgánica. Relaciones Interadministrativas", publicado en Revista Jurisprudencia Argentina 1962-III, páginas 77 y ss.

8 RIVERO, Jean, Droit Administratif, página 95/97; asimismo, Georges VEDEL trata la cuestión de las circulares o instrucciones de servicio y su real naturaleza jurídica, en 
Con respecto a la actividad calificada como interna se ha considerado clarificadora la distinción entre la relación orgánica y de servicio realizada por José Antonio García-Trevijano Fos, en virtud de la cual el funcionario no debe confundirse del todo con el órgano: mientras que los órganos no tienen derechos sino competencias, en el ámbito de la relación de servicio los agentes -en tanto individuos encargados de desarrollar una determinada función pública- poseen un conjunto de derechos y deberes, y dicho status puede verse afectado por esas medidas ${ }^{9}$. Como expresara Ernst Forsthoff en oportunidad de tratar las relaciones jurídicas entre órganos, la atribución de competencia no significa la concesión de un derecho subjetivo: "Las instituciones en cuanto tales no pueden ser titulares de derechos subjetivos, salvo el caso de que sean también personas jurídicas por habérseles reconocido capacidad jurídica" ${ }^{10}$, a lo cual agrega: "Cuando se transgrede una esfera de competencia, la autoridad afectada no es violada en sus derechos. Por esa

VEDEL, Georges Derecho Administrativo, Edición Española, Traducción de la Sexta Edición Francesa por Juan Rincón Jurado, Biblioteca Jurídica Aguilar, 1980, páginas 142/145; en el Derecho español un análisis de las instrucciones y circulares, con sus clasificaciones según su contenido (que es muy heterogéneo) y naturaleza jurídica de las mismas, en la obra de SANTAMARÍA PASTOR, Juan Alfonso, Fundamentos de Derecho Administrativo, Volumen I, Editorial Centro de Estudios Ramón Areces S.A., Madrid, 1991, páginas 727 y ss. Ciertamente, como ha expresado el citado jurista español, las instrucciones y circulares internas tienen su fundamento en la potestad autoorganizatoria y en el poder jerárquico, mediante las cuales los órganos superiores dirigen con carácter general la actividad de los inferiores.

9 GARCÍA-TREVIJANO FOS, Antonio, Tratado de Derecho Administrativo, Tomo III, Volumen 1, Editorial Revista de Derecho Privado, Madrid, 1970, página 466/468. En el mismo sentido puede verse COMADIRA, Julio R. "Algunos Aspectos de la Teoría del Acto Administrativo", publicado en Revista Jurisprudencia Argentina 1996-IV, páginas 750 y ss. Hartmut MAURER destaca que en el Derecho alemán se considera que el acto administrativa debe estar dirigido a producir efectos externos y por ello quedan fuera del concepto las órdenes de servicio que se refieren al funcionario como administrador, no obstante se advierte "...serán, sin embargo, actos administrativos cuando se refieran a él en cuanto persona autónoma (esto es, en un sentido personal). En el primer caso el servidor público se sitúa dentro del ámbito administrativo y en el segundo fuera de dicho ámbito", en MAURER, Hartmut, Derecho Administrativo Alemán, páginas 198/199.

10 FORSTHOFF, Ernst, Tratado de Derecho Administrativo, página 575. 
razón, los conflictos de competencia no son litigios jurídicos en torno a derechos subjetivos". ${ }^{11}$

De todo lo expuesto se desprende la importancia que tiene la teoría de la calificación jurídica, la que establece el correcto encuadramiento de los actos y situaciones más allá de su ropaje terminológico o nomen iuris.

En la doctrina argentina se han mencionado como ejemplo de actos generados a raíz de las relaciones interorgánicas los de colaboración y conflicto, de control y supervisión, de información y consulta, etc. Juan Carlos Cassagne considera que la actividad inter-orgánica "...presenta rasgos distintos en relación con el régimen jurídico de los actos administrativos, hecho que justifica su aislamiento conceptual" postulando la aplicación supletoria o analógica -según el caso- de las normas y principios que informan el régimen jurídico del acto administrativo ${ }^{12}$.

Por su parte Agustín Gordillo, entiende que si los actos tienen efectos jurídicos directos, se rigen por las mismas disposiciones y los mismos principios, es decir resulta aplicable el mismo régimen jurídico. En tal sentido considera que no existen razones para clasificarlos y definirlos separadamente "... sólo porque unos produzcan efectos hacia afuera y otros hacia adentro", por ello la distinción debe basarse “... prescindiendo

11 FORSTHOFF, Ernst, Tratado de Derecho Administrativo, páginas 575/576, dicho autor concuerda con la doctrina de George JELLINEK; al respecto, puede verse BEZZI, Osvaldo Máximo, en "La Competencia del Órgano Administrativo, publicado en la obra colectiva Acto y Procedimiento Administrativo, dirigida por Manuel María DIEZ, Editorial Plus Ultra, Buenos Aires, 1975, páginas 24 y ss.

12 CASSAGNE, Juan Carlos, Derecho Administrativo, Volumen II, Quinta Edición, Editorial Abeledo-Perrot, páginas 60 y ss. Dicho jurista señala que no rige en toda su dimensión el carácter de la ejecutoriedad y el principio de la estabilidad del acto administrativo, apuntando que difiere su publicidad y que no son en principio cuestionables ni en sede administrativa ni judicial. Fernando GARCÍA PULLÉS considera indispensable que a los actos interorgánicos e interadministrativos se les procure: “... una regulación normativa específica, que no se base sobre la analogía o la supletoriedad fundada en la opinión doctrinaria, sino sobre preceptos de Derecho positivo que, para iniciar, podrían declarar la plena aplicación de los principios de la Ley de Procedimientos Administrativos a su respecto", "Actividad Administrativa Interna, Interorgánica e Interadministrativa", página 344. 
de quienes son alcanzados por tales efectos"; y en este orden de ideas, estima que no es conveniente distinguir entre actos administrativos, actos inter-orgánicos y actos inter-administrativos"13.

Es dable considerar que la actividad administrativa resulta ser muy variada y esa heterogeneidad dificulta su regulación jurídica homogénea. Ante el numeroso conjunto de actos cabría quizá reflexionar que podría constituir un error metodológico partir de un determinado concepto de acto administrativo y constituir un punto de vista absoluto; en tal sentido, por ejemplo, cuando la autoridad superior dicta un acto que con motivos fundados dispone la avocación para resolver un asunto sustituyendo al inferior o en el caso de que se disponga por acto fundado la intervención administrativa de un ente descentralizado, podría considerarse que la calificación de esos actos como administrativos resulta jurídicamente lógica. En el mismo sentido, en el ámbito de las llamadas relaciones interadministrativas -y especialmente- las que se entablan entre distintas esferas del gobierno, resulta frecuente la emisión de actos administrativos y la celebración de convenios, por ejemplo con: el dictado de un permiso de uso de un bien del dominio provincial a favor de un municipio; el acto del P.E. mediante el cual se convalida o aprueba una ordenanza urbanística; el acto del ejecutivo provincial por el que se acepta la cesión de bienes efectuada por un municipio, etc. ${ }^{14}$. Ciertamente, como ha entendido Juan

13 GORDILLO, Agustín, Tratado de Derecho Administrativo, Tomo 3, páginas 17/18. El destacado autor expresa que los efectos jurídicos pueden ser relativos a particulares, a funcionarios o entes administrativos, sin que exista a su criterio diferencia importante de régimen jurídico. En el mismo sentido, DROMI, Roberto, Derecho Administrativo, Ediciones Ciudad Argentina, Sexta Edición, 1997, página 223.

14 En el orden provincial se han producido controversias jurídicas entre la provincia y los municipios, particularmente con relación a tierras aluvionales originadas en cursos de agua; no obstante pertenecer a dos esferas de gobierno esos conflictos no resultan razonables en cuanto afectan el principio de unidad del ordenamiento estatal. En el orden nacional ver las consideraciones expuestas por Juan Carlos CASSAGNE, especialmente al abordar la solución de conflictos inter-administrativos pertenecientes a una misma esfera de gobierno, en su obra Derecho Administrativo, Volumen II, páginas 64 y ss., y el estudio de Fernando R. GARCÍA PULLÉS, "Actividad Administrativa Interna, Interorgánica e Interadministrativa”, 
Carlos Cassagne no rigen en toda su dimensión algunos caracteres o prerrogativas del acto administrativo y otras notas de su régimen, pero las diferencias no necesariamente justificarían su expulsión conceptual. En todo caso podría tratarse de una especie o clase de acto administrativo. A su vez, puede señalarse que no todos los actos interorgánicos pueden asimilarse a los administrativos lo que no obsta a que se le apliquen como han entendido Juan Carlos Cassagne y Juan Francisco Linares, los principios del régimen jurídico del acto administrativo. En tal orden de ideas, las circulares o instrucciones que contienen directivas generales de buena administración o establecen prescripciones de carácter técnico ${ }^{15}$, los actos de la Administración de colaboración, de control interno, las medidas preparatorias de la decisión administrativa como los informes y dictámenes, acto este último que en el campo jurídico cobra relieve significativo, representan a los llamados "actos de administración" en cuanto no han de producir efectos jurídicos directos ${ }^{16}$ ni propiamente trascienden el ámbito de la organización administrativa.

\section{La figura del dictamen ${ }^{17}$ : naturaleza, función, requisitos, clasificaciones, apartamiento del juicio por el órgano decisor y la teoría de la subsanación}

En el ámbito de la actividad preparatoria de la decisión administrativa cobra relieve la función de la Administración

ob.cit., página 345 y ss. La Ley N 19.983 regula el tratamiento de los conflictos de naturaleza pecuniaria, resultando el órgano competente para resolver los reclamos el Poder Ejecutivo o el Procurador del Tesoro de la Nación, según el monto. Los conflictos de competencia se regulan en la ley nacional de procedimientos administrativos.

15 DIEZ, Manuel María, Derecho Administrativo, Tomo II, página 212.

16 GORDILlO, Agustín, Tratado de Derecho Administrativo, Tomo 1, Capítulo X-4.

17 La historia del Derecho Romano nos enseña la importancia del dictamen. Las respuestas de las cuestiones de derecho de los jurisconsultos que gozaban del ius publicae respondendi, dan origen a nuevas reglas jurídicas, gracias al emperador Augusto, quien concedió a los titulares de este derecho, la facultad de que sus dictámenes, sobre puntos de derecho, prevalecieran o tuvieran una autoridad superior a los expedidos por los jurisconsultos que no tenían este privilegio. El emperador Adriano había dispuesto que cuando hubiera 


\section{consultiva $^{18}$, pues mediante ella se ilustra de manera anticipada al dictado de un acto administrativo ${ }^{19}$, con el respectivo juicio al}

unanimidad sobre un punto entre los jurisconsultos que gozaban del ius publicae respondendi, el juez debía atenerse al dictamen de ellos; pero si había divergencia, podía seguir la opinión que juzgara más acertada. De acuerdo a la máxima romana, "Responsa prudentium sunt sententiae et opiniones eorum, quibus permissum est iura condere", lo cual significa que las respuestas de los hombres prudentes son las sentencias y opiniones de aquéllos a los que está permitido redactar leyes; de acuerdo al catedrático Pablo FUENTESECA: "Aquí Gayo aporta una explicación que más tarde repetirá Justiniano (Ist. 1,1,8) y ambos permiten afirmar: 1.- los responsa prudentium correspondían a aquellos a quienes se les había permitido la función de iura condere y por tanto realizaban una función de iuris conditores; 2.- si éstos están de acuerdo en una misma opinión común, el responsum obtiene una eficacia de lex (legis vicem obtinet) vinculante para los iudices, pero si aquellos disienten, el iudex podrá seguir la opinión que prefiera según consta en un rescripto de Adriano", en FUENTESECA, Pablo, "La Eficacia Vinculante de los Responsa Prudentium Romanos", Anuario da Facultade de Dereito da Universidade da Coruña, Número 10, 2006, España, páginas 413/417, asimismo, se encuentra disponible una versión digital en la página web: http://ruc.udc.es/dspace/ bitstream/handle/2183/2453/AD-10-20.pdf? sequence=1. Puede a su vez consultarse la obra de FERNÁNDEZ DE LEÓN, Gonzalo, Diccionario de Derecho Romano Editorial S.E.A., Buenos Aires, 1962, Buenos Aires, voces Respuestas de los Jurisconsultos y Jurisconsultos. Jus Publicae Respondendi. Ver también la voz Dictamen, en la enciclopedia jurídica Omeba, por el Dr. Arturo GALLARDO RUEDA.

18 En cuanto al dictamen ver el completo estudio de MURATORIO, Jorge I., “El Dictamen Jurídico en la Administración Pública Nacional”, publicado en Revista de Derecho Administrativo, № 41, Editorial Depalma, Buenos Aires, 2002, páginas 535 y ss., asimismo, en dicha obra se efectúa un análisis relativo a la distinción entre los informes y dictámenes. En el Derecho comparado, alguna doctrina a la que no adherimos, ha considerado que efectuar una distinción entre las figuras del informe y el dictamen carece de auténtico interés, ver GONZÁLEZ NAVARRO, Francisco y BLANCO DE TELLA, Luis, en la obra conjunta Organización y Procedimientos Administrativos, Editorial Montecorvo S.A., Madrid, 1975, página 301; puede verse asimismo el enfoque de DROMI, Roberto, Derecho Administrativo, Sexta Edición, Editorial Ciudad Argentina, Buenos Aires, 1997, páginas 311 y ss.

19 De manera genérica, cabe citar los trabajos de LUQUI, Juan Carlos, “El Dictamen Jurídico. Algunas Consideraciones Sobre su Forma, Contenido y Función”, publicado en Revista Jurisprudencia Argentina 1954-IV, páginas 44 y ss., así como lo expuesto por TORRES, Ismael Fabián, "Administración Consultiva y Dictamen Jurídico, (Pautas para una Correcta Elaboración)", publicado en Revista Argentina del Régimen de la Administración Pública, Tomo XXVI, № 304, Buenos Aires, 2004,páginas 83 y ss. Con distinto alcance, aunque haciendo alusión al dictamen como opinión jurídica, puede consultarse la obra de ATIENZA, Manuel, Curso de Argumentación Jurídica, Editorial Trotta, Primera Edición, Segunda Reimpresión, España, páginas 730 y ss., en donde, con cita de la obra de Manuel GONZÁLEZ MENESES denominada Cómo Hacer Dictámenes (Ensayo sobre la Formación del Jurista), Editorial Gredos, 2007, Madrid, España, se analiza al denominado dictamen "de escuela", entendido como aquel 
órgano de la Administración activa con competencia decisoria en la materia de la que se trate. El resultado de dicha actividad se plasma en un dictamen, el cual consiste en un juicio fundado en una ciencia determinada ${ }^{20}$, que emiten organismos técnicamente calificados a fin de colaborar en el encuadre y comprensión del asunto bajo análisis, para permitir así que el órgano de la Administración activa efectúe una decisión ajustada al ordenamiento jurídico, tendiendo a satisfacer de mejor manera los principios de justicia y legalidad ${ }^{21}$.

que consiste en un caso práctico inventado que se propone a los estudiantes o a quienes concurren a una oposición, con la finalidad de que muestren sus conocimientos teóricos y prácticos. Allí se describen las distintas fases en la elaboración de un dictamen, entre las que consideramos como las más importantes a la denominada "calificación jurídica", "identificación de alternativas", "argumentos a favor y en contra", "decisión" y "redacción del texto".

20 Ver las consideraciones efectuadas por Pedro J.J. COVIELLO en el prólogo a la obra de GOROSTEGUI, Beltrán, El Dictamen Jurídico Administrativo, Editorial El Derecho, Colección Académica, Buenos Aires, 2010, páginas 15/21. Como bien ha dicho el doctrinario prologuista: "El dictamen debe necesariamente exponer los hechos relevantes y no ser dogmático [...] El asesor en su dictamen no debe usar el potencial, sino decir lo que a su juicio corresponde hacer, y mediante una propuesta que sea clara, breve y concisa. Ver también LUQUI, Juan Carlos, Burocracia en Broma y en Serio, Ediciones Depalma, Buenos Aires, 1985, Estudio “Dictámenes y Asesores”, "Método para la Preparación del Dictamen”, páginas 252 y ss. Como sostuviera Jorge Luis POSIK: "El asesoramiento reclama enjundia, lógica, espíritu crítico, prudencia, obrar conforme a la recta razón, sensibilidad para apreciar los intereses en juego y los factores humanos; las mutaciones producidas en el ámbito profesional y social, rigor en el pensamiento, el abrazo con el juicio fundado, pero todo ello siempre con la mirada dirigida a establecer lo que es justo. El jurista debe ajustarse a las circunstancias concretas y objetivas del caso, penetrando los resquicios ocultos, aprender el lenguaje de lo implícito, para pronunciarse con extrema claridad, no sobre abstracciones, aunque sean creativas y menos aún convertir el dictamen en una exposición predominantemente doctrinaria o académica, que pueda ensombrecer la apreciación de las circunstancias que satisfacen al juicio más justo y razonable." , en POSIK, Jorge Luis, La Asesoría General de Gobierno de la Provincia de Buenos Aires. Su Función en el Ordenamiento Jurídico Institucional, Editorial Scotti, Buenos Aires, 2007, página 53.

21 Como ha sostenido Juan Carlos LUQUI respecto de la función que cumple el asesor: "No le es permitido defender otra cosa que la regular aplicación del derecho, ni tampoco pensar que por ser abogado de la Administración debe constituirse en enemigo del particular [...] En el propio beneficio del Estado es aconsejable el respeto por los intereses particulares legítimos, aunque sólo sea para evitar el riesgo de que los particulares afectados encuentren en la autoridad judicial el amparo que les negó la autoridad administrativa.", LUQUI, Juan Carlos, 
En cuanto a la estructura del dictamen, por lo general, salvo alguna excepción ${ }^{22}$, las normativas procedimentales no lo prevén, habiendo sido desarrolladas dichas facetas por parte de la doctrina, los manuales de estilo de los organismos asesores ${ }^{23}$, así como por los usos y prácticas de cada organismo.

Como bien se ha dicho, el dictamen jurídico no libera de responsabilidad al funcionario que haya de emitir el acto administrativo $^{24}$, en cuanto a la decisión que ese acto implica

Burocracia en Broma y en Serio, páginas 246/247. Cabe destacar, en el orden nacional la función que cumple en esta materia la Procuración del Tesoro de la Nación, ver el estudio de CASSAGNE, Juan Carlos, "Función y Organización de los Asesores Jurídicos del Estado", Publicado en Revista El Derecho, Tomo 57, páginas 861 y ss., y en la provincia de Buenos Aires, respecto de la Asesoría General de Gobierno puede verse la obra de POSIK, Jorge Luis, La Asesoría General de Gobierno de la Provincia de Buenos Aires. Su Función en el Ordenamiento Jurídico Institucional; asimismo, en relación a dicho órgano, ver su encuadre legal en los artículos 36 a 43 de la Ley de Ministerios de la provincia de Buenos Aires, Ley $N^{0} 14.989$, donde se la caracteriza respondiendo a una estructura administrativa desconcentrada respecto del poder ejecutivo, la cual por su relación con la Secretaría Legal y Técnica podría desnaturalizar su independencia.

22 En tal sentido, puede consultarse el artículo 41 del Capítulo III "Dictámenes e Informes" de la Ley I N 89 de la provincia de Misiones, conforme al cual: "El dictamen o informe técnico será requerido cuando sea obligatorio en virtud de norma legal expresa o sea conveniente para resolver la cuestión planteada.

Los dictámenes o informes contendrán:

a) resumen de la cuestión objeto de la consulta;

b) relación de los antecedentes que sirvan como elementos de juicio para resolver;

c) opinión concreta y fundada en normas jurídicas o técnicas aplicables al caso consultado.

Los dictámenes o informes se referirán concretamente a los antecedentes y circunstancias en que hayan sido requeridos.".

23 Así, y a titulo meramente enunciativo, se remite al Manual de Estilo de la Procuración del Tesoro de la Nación publicado en: https://www.ptn.gob.ar/images/files/NUEV0\%20 MANUAL\%20ESTILO.pdf, así como al Manual del Dictamen Legal - Lineamientos Generales de la Asesoría General de Gobierno de Catamarca, al cual puede accederse mediante el acceso a la siguiente página web: https://www.portal.catamarca.gob.ar/media/uploads/ organismo/documentos/asesoria-general-de-gobierno-18/manualf.pdf

24 Ver MARIENHOFF, Miguel S. Tratado de Derecho Administrativo, Tomo I, página 95/96. Sin perjuicio del razonamiento expuesto en el texto, el mismo debe ser matizado teniendo en cuenta, como ha considerado Carlos Rodolfo BARRA: " . . la medida de esa responsabilidad deberá ser valorada conforme con la incidencia que el dictamen ha debido tener, según su especificidad, sobre la voluntad del decisor." , y aclara que al momento de interpretar responsabilidades, no se halla en la 
a consecuencia del ejercicio de una competencia administrativa previamente atribuida, pero es principalmente en esa argumentación jurídica, en la que consiste el juicio que en el dictamen se expresa, el punto de apoyo o respaldo jurídico que aquella decisión vaya a tener ${ }^{25}$, lo cual evidencia lo relevante de la actividad asesora, dadas las implicancias involucradas. Con el cumplimiento de dicho trámite esencial se satisface una garantía protectora de los derechos e intereses de los particulares y aseguradora del acierto de la decisión adoptada. De esta manera, al fundamentar adecuadamente la decisión se tiende a disminuir reproches y responsabilidades por el ejercicio de la actividad administrativa. Por ello, la teoría de la "subsanación", propuesta como remedo a fin de sanear la omisión de dichos dictámenes (constituyendo, como fuera expuesto un trámite esencial dentro de las actuaciones), en conjunción con la muchas veces invocada teoría de la conservación de los actos

misma condición una persona física que no fuera abogado y que hubiera requerido un dictamen jurídico, ya que sería irrazonable e injusto "... pretender que el decisor asuma en tales condiciones cualquier tipo de responsabilidad, lo que no excluye, por supuesto, la invalidez del acto decisorio y la imputabilidad y responsabilidad de la persona jurídica a la que pertenece el decisor.", en BARRA, Carlos Rodolfo, "Administración y Actividad Consultiva", publicado en la obra colectiva Cuestiones de Procedimiento Administrativo, Jornadas organizadas por la Universidad Austral, Facultad de Derecho, Ediciones RAP, Buenos Aires, mayo de 2006, especialmente páginas. 550/551 y nota 87. En definitiva, debe realizarse una discriminación entre la responsabilidad del órgano emisor del acto, como una situación diferenciada de la responsabilidad del autor del dictamen, en tal caso la responsabilidad del emisor del dictamen: “... será mensurada de acuerdo con las reglas de su propia ciencia, que permitirán, por ejemplo, calificar al error como inexcusable o no.", ob. cit., loc. cit. Cabe añadir las reflexiones de Juan Carlos LUQUI, quien expresara: "Quien dictamina tiene una doble responsabilidad: primero, la de cuidar la regular aplicación de la norma jurídica, con lo que cuida la responsabilidad y reputación del funcionario llamado a decidir; la otra le es propia, está consagrada por el Código Penal (arts. 271 y 272). Por sobre estas responsabilidades está el buen nombre y reputación del asesor.", en LUQUI, Juan Carlos, Burocracia en Broma y en Serio, Ediciones Depalma, Buenos Aires, 1985, Estudio “Dictámenes y Asesores", página 247.

25 GOROSTEgUI, Beltrán, El Dictamen Jurídico Administrativo, Prólogo de Pedro J. J. COVIELLO, Editorial El Derecho, Colección Académica, Buenos Aires, 2010, en donde se expresa: "La motivación del acto administrativo encuentra su fuente natural de fundamentos en la motivación del dictamen jurídico previo.", ob. cit., página 99; su relación con el elemento "causal" es destacada en el citado estudio de Rodolfo Carlos BARRA, "Administración y Actividad Consultiva", publicado en la obra colectiva Cuestiones de Procedimiento Administrativo, Jornadas organizadas por la Universidad Austral, páginas 533/535. 
jurídicos, no debería ser receptada como principio ${ }^{26}$, máxime cuando la motivación "aparecida" luego del dictado del acto puede responder a una construcción generada en realidad con posterioridad al mismo ${ }^{27}$.

\author{
El cumplimiento de la evacuación de la consulta jurídica \\ cuando ello es solicitado de manera facultativa o cuando resulte
}

26 La Corte Suprema de Justicia de la Nación en la causa "Duperial I.C. c. Nación Argentina", publicada en Fallos 301: 953, aplicó la teoría de la subsanación en el marco de un recurso; la Suprema Corte de la Provincia de Buenos Aires en la causa "Club Estudiantes de la Plata c/Municipalidad de la Plata s/Amparo", causa B-64.413, sentencia del 4 de septiembre del año 2002, ha invalidado un acto de la Municipalidad de la ciudad de La Plata, con motivo de haberse emitido sin el dictamen jurídico previo, reputado esencial en la materia tratada, devolviendo las actuaciones administrativas a la accionada a fin de que observara los trámites y procedimientos esenciales para su adecuado tratamiento, ver el voto del Sr. Juez, Dr. Héctor NEGRI. Sobre la ausencia del dictamen jurídico, Tomás HUTCHINSON ha considerado: "El acto dictado sin haberse cumplido con el dictamen de la Asesoría es, en principio, nulo; sin embargo, podría ocurrir que ello no fuera así si el acto no aparece con vicio intrínseco alguno. Imaginemos, por ejemplo, un acto dictado en ejercicio de facultades regladas que se adecúa estrictamente a lo que establece la norma. La sanción de nulidad del acto sería una declaración de la nulidad por la nulidad misma.", en HUTCHINSON, Tomás, Procedimiento Administrativo de la Provincia de Buenos Aires, páginas 210/211. Por otra parte, se ha sostenido una crítica a la teoría de la subsanación, poniendo el acento en la importancia que revisten las formas en el Derecho público, las cuales trascienden el exclusivo interés de las partes, y atienden primordialmente a preservar el interés público, ver Julio R. COMADIRA con Laura MONTI (colaboradora) en Procedimientos Administrativos. Ley Nacional de Procedimientos Administrativos. Anotada y Comentada, Tomo I, ob. cit., páginas 320/321 en donde se cita el criterio de Fabián 0. CANDA; a su vez, se remite a las consideraciones que se exponen al tratar el vicio de forma en la presente obra. Por otra parte, desde antaño la doctrina de la Procuración del Tesoro ha considerado que no procede declarar la nulidad de un acto por falta de dictamen previo si aquella omisión es subsanada posteriormente (ver Revista Dictámenes 191:140), y que los dictámenes posteriores purgan el vicio de la omisión del dictamen previo (ver Revista Dictámenes 144:148, 193:110 y 197:162, entre otros); todo ello siempre que la cuestión resuelta estuviera arreglada a derecho y, por lo tanto, la omisión formal resultara salvable; en el mismo sentido, consultar el Dictamen $N^{\circ} 62$, emitido en el marco del Expediente $N^{0}$ 10.929/08 de fecha 25 de enero del año 2010; Dictamen $N^{0} 31$, emitido en el marco del Expediente $N^{0} 43.809 / 08$ de fecha 8 de octubre del año 2010 y Dictamen N ${ }^{0} 407$, emitido en el marco del Expediente N S01-0130704/07 de fecha 28 de junio del año 2007.

27 GORDILlO, Agustín A., Tratado de Derecho Administrativo, Tomo 3, ob. cit., Capítulo X-22, quien, en relación, y específicamente refiriéndose a la motivación, la cual guarda conexidad con esta materia, sostiene: "Si [...] se admite [...] la motivación ulterior ya se entra en el terreno de aceptar que se brinden explicaciones o excusas de lo ya hecho, no fundar por qué se lo hace. Alli entramos en el terreno de la fundamentación o motivación fabricada, ad hoc del acto ya dictado, lo que constituye un vicio de razonamiento en cualquier ciencia.". 
menester por haber sido preceptivamente ordenada por la normativa, junto con la actividad de contralor de la actividad administrativa (v. gr.: vista del órgano Fiscal de Estado ${ }^{28}$ o informe de la Contaduría General en el ámbito de las provincias), cumplen una función colaborativa en la formación de la motivación o fundamentación del acto administrativo, y orientan respecto de la concordancia entre la actividad administrativa y la finalidad pública concreta que se persiga. Tan importante es esa intervención que, por ejemplo, el apartamiento por parte del órgano competente de la Administración activa respecto del juicio emitido en un dictamen sin explicitar las razones fundadas de ello, determinaría la nulidad del acto $^{29}$. Lo expuesto, no significa que la autoridad competente para decidir se halle obligada a compartir las razones y conclusiones expuestas en el dictamen, ni que el texto del mismo genere necesariamente derechos a favor de los particulares, no obstante obligar al órgano administrativo a fundar su decisión rebatiendo las razones y el juicio expresados por el órgano consultivo, dando fundamentos de peso a tales fines, enriqueciendo de esta manera la función

28 TRIBIÑO, Carlos R. El Fiscal de Estado, Editorial Ábaco de Rodolfo Depalma, 2001, Buenos Aires, especialmente Capítulo VI, páginas 99 y ss.

29 En la provincia de Buenos Aires existe una línea jurisprudencial fijada por la Suprema Corte de la Provincia, en el sentido que el apartamiento respecto del dictamen jurídico, sin considerar los fundamentos del mismo ni las medidas en él propiciadas, conllevan la declaración de la nulidad del acto administrativo: "Sin embargo, pese a lo señalado en el dictamen jurídico, al tiempo de dictar la resolución segregativa, la autoridad pública omitió lisa y llanamente considerarlo. Si ello es de por sí inválido, tanto más lo es cuando en el presente caso el servicio jurídico propiciaba la aplicación de una sanción distinta (y menos gravosa) que la aconsejada por la instrucción...", en Causa B.57.387, caratulada "V., S. B. contra Provincia de Buenos Aires (Policía). Demanda Contencioso Administrativa", del 7 de septiembre del 2016, especialmente el voto del Sr. Juez, Dr. Daniel SORIA. En este orden, existe una doctrina judicial reiterada que reafirma la importancia de fundamentar jurídicamente cuando la autoridad administrativa con competencia decisora se aparta de los fundamentos del dictamen; entre otras B.63.367, B.62.523, B.64453, todas ellas, a la luz de lo prescripto en el inciso c) del artículo 108 del Decreto Ley Nº 7647/70. En el ámbito de la provincia de Buenos Aires, ver la obra de Carlos A. BOTASSI y Miguel H. OROZ, Procedimiento Administrativo de la Provincia de Buenos Aires. Decreto -Ley 7647/70 y Ordenanza General 267/80, Segunda Edición Corregida, Actualizada y Ampliada, Librería Editora Platense, La Plata, 2011, parágrafo 239 "Apartamiento del Criterio Señalado en los Dictámenes y la Vista", páginas 291 y ss. 
administrativa al demostrar de manera más explícita y acabada la satisfacción del principio de legalidad y juridicidad.

En el orden jurídico nacional, y a título meramente ejemplificativo, la recepción normativa del dictamen jurídico se consagra en el inciso d) del artículo $7^{\circ}$ del Decreto Ley $\mathrm{N}^{\circ} 19549 / 72$, en el cual se establece: “(...) considérase [...] esencial el dictamen proveniente de los servicios permanentes de asesoramiento jurídico cuando el acto pudiere afectar derechos subjetivos e intereses legítimos.”. Otra demostración de dicha intervención se manifiesta en las contiendas negativas y positivas de competencia, en las que, de conformidad con el segundo párrafo del artículo $5^{\circ}$ del citado Decreto Ley: "La decisión final de las cuestiones de competencia se tomará, en ambos casos, sin otra sustanciación que el dictamen del servicio jurídico correspondiente $\mathrm{y}$, si fuere de absoluta necesidad, con el dictamen técnico que el caso requiera.". Por su parte, la reglamentación de la normativa nacional, en su artículo 92, referido al recurso jerárquico, precisa que en su tramitación: “(...) se recabará obligatoriamente el dictamen del servicio jurídico permanente."30.

Consideramos que la interpretación del texto del inciso d) del artículo $7^{\circ}$ del Decreto Ley $\mathrm{N}^{\circ} 19549 / 72$ debe ser realizada de manera inclusiva y promotora de la emisión de los dictámenes jurídicos, evitando toda interpretación restrictiva o reticente a su producción ${ }^{31}$, por lo que cabe observar críticamente dicha hermenéutica. Como expresa Ezequiel Cassagne: “...el dictamen jurídico debiera ser obligatorio y previo a todo

30 La doctrina distingue, con apoyo en la normativa nacional, cuando se trata de dictámenes e informes de efectos probatorios, al respecto, ver GOROSTEGUI, Beltrán, El Dictamen Jurídico Administrativo, ob. cit., página 62 y ss. En tal sentido, el subinciso 2 del inciso f) del artículo $1^{\circ}$ del Decreto Ley 19.549/72, establece que la Administración debe: “ . . requerir y producir los informes y dictámenes necesarios para el esclarecimiento de los hechos y de la verdad jurídica objetiva.".

31 Confrontar con el criterio establecido por la Corte Suprema de Justicia en el fallo “Cerámica San Lorenzo I.C.S.A. c/Gobierno Nacional”, de fecha 30 de septiembre de 1976, publicado Fallos 311:2453, y en Revista El Derecho, Tomo 70, páginas 376 y ss., con nota de Juan Carlos CASSAGNE, "Inmutabilidad del Acto Administrativo Dictado con Prescindencia del Dictamen Jurídico en el Procedimiento Impositivo". 
acto administrativo, con independencia de si llegare a afectar derechos e intereses de los particulares, en la medida que la función consultiva en derecho [...] no sólo importa una garantía frente al administrado, sino que representa una garantía y control de la legitimidad administrativa." 32 .

Por último, cabe destacar que en la doctrina y legislación se consagran distintos criterios clasificatorios respecto de los dictámenes jurídicos ${ }^{33}$, de los que resulta: a) Facultativos o Voluntarios/Obligatorios o Preceptivos y; b) Vinculantes/No Vinculantes.

En relación al primer criterio clasificatorio, hay que señalar que cuando la norma establece la obligatoriedad de la producción del dictamen jurídico, convirtiéndolo en preceptivo, su incumplimiento constituye la omisión de un trámite esencial ${ }^{34}$, deviniendo por ello nulo el acto administrativo dictado en consecuencia, no siendo ello convalidable a posterior $i^{35}$.

Con respecto a los dictámenes vinculantes, serían aquellos en los que la Administración activa está obligada a requerirlos y a aceptar sus conclusiones. De receptar la categoría es

32 Ver Ezequiel CASAGNE, "El Dictamen de los Servicios Jurídicos de la Administración", publicado en Diario La Ley del día 15 de agosto de 2012, y Tomo 2012-D, páginas 1340 y ss. Pueden verse también las consideraciones expuestas en la excelente obra de GOROSTEGUI, Beltrán, El Dictamen Jurídico Administrativo, ob. cit., páginas 45/50, con respecto a la necesidad de tornar obligatorio al dictamen, incluso cuando pudiera comprometer a la hacienda pública sin afectar la esfera jurídica de los particulares; ver también FIORINI, Bartolomé, Derecho Administrativo, Tomo l, ob. cit., página 325.

33 CANASI, José, Derecho Administrativo, Volumen I. Parte General, Ediciones Depalma, Buenos Aires, 1972, páginas 283 y ss.; GORDILLO, Agustín, Tratado de Derecho Administrativo, Tomo 1, ob. cit., Capítulo X-4/5; DROMI, Roberto, Derecho Administrativo, ob. cit., páginas 316/318, DIEZ, Manuel María, Derecho Administrativo, Tomo I, Editorial Bibliográfica Omeba Argentina S.R.L., 1963, Buenos Aires, páginas 173/174; ALESSI, Renato, Instituciones de Derecho Administrativo, Tomo I, ob. cit., páginas 128/129.

34 Puede verse el estudio de SANTOS, Alejandra Marcela, "Algunas Consideraciones Acerca del Dictamen Jurídico Posterior y de la Denominada <<Teoría de la Subsanación»>", publicado en Diario El Derecho (EDA), del día viernes 31 de marzo del año 2017.

35 GARCÍA DE ENTERRÍA, Eduardo y FERNÁNDEZ, Tomás Ramón, Curso de Derecho Administrativo, Segunda Edición, Tomo II, Editorial Civitas S.A., Madrid, 1989, página 421. 
forzoso reconocer que la misma pone en jaque al principio de distribución de competencias, porque implicaría una excepción a las reglas generales ${ }^{36}$, y surge el interrogante referido a cuál voluntad prevalecerá: es decir, la del órgano decisor o la del consultivo. Se ha destacado el juicio de Bartolomé Fiorini e Ismael Mata, quienes han sostenido que en el caso de los dictámenes de las Comisiones de Preadjudicación, los mismos tienen carácter vinculante, y consecuentemente son impuestos al órgano administrativo ${ }^{37}$. Evidentemente, se trata del ejercicio de una competencia predominantemente técnica por parte de esos órganos colegiados, pudiendo algunos incluso argumentar que en rigor lo que se produjo fue una traslación de la competencia decisora a favor de dichos órganos. Sobre este aspecto, ha dicho Miguel Santiago Marienhoff: "Ningún dictamen de órganos consultivos puede tener semejante alcance; si la ley les atribuyese tales efectos, el dictamen dejará de tener carácter consultivo, debiéndose regir entonces por otras reglas. La esencia de tales dictámenes y la índole de las funciones de dichos órganos excluye aquellos efectos." ${ }^{38}$. Cabe añadir el

36 Eduardo GARCÍA DE ENTERRÍA, y Tomás Ramón FERNÁNDEZ han considerado esta categoría supone la existencia de una competencia compartida entre el órgano activo y el órgano consultivo, en GARCÍA DE ENTERRÍA, Eduardo y FERNÁNDEZ, Tomás Ramón, Curso de Derecho Administrativo, Segunda Edición, Tomo II, ob. cit., loc. cit., ut supra.

37 GOROSTEGUI, Beltrán, El Dictamen Jurídico Administrativo, ob. cit., páginas 54/55; José Antonio GARCÍA TREVIJANO, destacando los juicios de Cino VITTA y Enrique PRESUTTI, ha analizado la categoría de los dictámenes o informes vinculantes, señalando los criterios sostenidos por la doctrina, los cuales oscilan entre aquellos que conciben a dichos dictámenes 0 informes como verdaderas autorizaciones, de aquellos que entienden que dichos dictámenes o informes integran un acto complejo junto con la decisión final. A juicio de este autor: "... si la vinculación es absoluta, el órgano informante es coautor o cooperador necesario del acto final, y de aquí que su responsabilidad sea mayor que en los demás casos."., ver GARCÍA TREVIJANO José Antonio, Los Actos Administrativos, página 321.

38 MARIENHOFF, Miguel S., Tratado de Derecho Administrativo, Tomo I, ob. cit., páginas 96/97. En la doctrina también se distingue entre dictamen favorable y el vinculante; en tal sentido, Beltrán GOROSTEGUI adhiere al criterio que sostiene que los favorables son obstativos, en lugar de vinculantes, aunque en la práctica no parece claro que los efectos entre unos y otros difieran, en GOROSTEGUI, Beltrán, El Dictamen Jurídico Administrativo, ob. cit., página 55. En rigor, podría sostenerse que aquel dictamen favorable exigido por 
criterio expuesto por Manuel María Diez, quien moduló el alcance del eventual carácter vinculante del dictamen, en el sentido que la Administración activa:

“ (...) solamente cabría aceptar que no se tomase una resolución contraria. Por ello, y si la consulta fuera en materia disciplinaria, el órgano de la Administración activa no podría aplicar una pena más grave que la que señalase el cuerpo consultivo, pero podría no aplicar ninguna pena o infligir una más suave."39

La opinión del maestro es plausible, no obstante lo cual no aparece tan clara la situación en aquellos casos en los que la opinión emitida en el dictamen no admite modulaciones, tal como ocurriría si mediante el mismo se determinara una aceptación o un rechazo, por ejemplo, de la aplicabilidad de una disposición normativa. En ese caso, el órgano decisor no podría modular su decisión ni en más ni en menos, con lo cual podría seguir argumentándose que se produjo una traslación en la competencia, o incluso afirmarse, como lo sostiene parte de la doctrina italiana y fuera oportunamente citado, que se trataría de un acto complejo.

la normativa jugaría como una condición suspensiva a los fines de la continuidad del trámite, más que como una autorización en sentido estricto. Como casos de dictámenes vinculantes previstos explícitamente en la normativa, cabe mencionar el artículo 39 de la ley 11.184 de la provincia de Buenos Aires, denominada "Ley de Reconversión de la Provincia de Buenos Aires", determinó la creación de una Comisión Bicameral en el ámbito de la Legislatura Provincial, que tiene, entre sus competencias la de: “...c) (Inciso DEROGADO por Ley 13810) emitir dictámenes vinculantes en las materias tratadas en los artículos $6^{\circ}, 7^{\circ}, 35,36$ y 37 de la presente ley; d) emitir dictamen vinculante en los casos de reformulaciones y/o rescisiones contractuales contempladas en el capítulo II de la ley 10.867, modificado por la ley 10.923; y e) emitir dictamen vinculante sobre la prórroga del plazo inicial de la emergencia, con treinta días hábiles administrativos de anticipación a su vencimiento.". Con respecto a los dictámenes médicos de juntas periciales, cabría considerar, por la fuerza obligatoria que ordinariamente se les reconoce, que los mismos no expresan un mero parecer o juicio, ya que generalmente se cuenta con variables objetivas y científicamente probadas o tasadas a fin de su emisión.

39 DIEZ, Manuel María, El Acto Administrativo, Segunda Edición, Tipográfica Editora Argentina, 1961, Buenos Aries, páginas 45/46. 